\title{
Changing long-term care provision at the local level in times of austerity - a qualitative study
}

\section{GRISTIANO GORI*}

\begin{abstract}
In the first decade of the century, long-term care (LTC) policies for dependent older people in Italy were improved with respect to both the availability of public funds and the quality of services. At the turn of the decade, however, cost-containment and austerity measures were imposed as an overall priority for the public sector and this goal also affected the LTC sector. This article explores the effects produced by cost-containment policies, which widened the gap between care needs and available public funding, on the provision of LTC services at the local level in Italy during the economic crisis. The study is based on 34 semi-structured interviews with services managers employed in Italy's publicly funded LTC system. Data were analysed with the framework analysis method and six cross-cutting thematic categories were identified that depict, according to the interviewees, the main transformations that occurred in the provision of LTC at the local level as a consequence of cost-containment policies. 'Uncertainty' refers to the inability to predict what direction the LTC system is going to take in the foreseeable future. 'Short-termism' illustrates the pressure to focus excessively on day-to-day service delivery at the expense of a medium- to long-term view of their future. 'Endangering quality' describes the risk of not being able to maintain the level of quality of care achieved so far. 'Allocative tensions' refers to the tensions due to the increasing requirement to ration the provision of public LTC services. 'Unequal re-familiarisation' represents the very different impacts of the trend of re-familiarisation depending on families' financial situation. 'Inappropriate care' depicts the rising number of older people receiving public care interventions that are not appropriate to meet their needs.
\end{abstract}

KEY WORDS - cost-containment policies, long-term care, local welfare, Italy.

\section{Introduction}

Long-term care (LTC) policies for older people have followed heterogeneous paths across Europe during the recent period of economic austerity (Greve 2017a). In some countries, most notably Germany (Nadash, Doty

* Department of Sociology and Social Research, University of Trento, Italy. 
and von Schwanenflugel 2017), major changes have been introduced to improve the system and increase public funding, while in others, such as Sweden (Greve 2017b) and Finland (Waldhausen 2014), the policies already in place have not been substantially modified by the change in the economic climate. In several countries, since the second half of the 2000 and in particular since 2010 , cost-containment policies have been applied to LTC. These policies have been introduced in countries with different LTC policy arrangements (Gori, Fernandez and Wittenberg 2015) and care regimes (Bettio and Plantenga 2004), such as the Netherlands (Maarse and Jeurissen 2016), United Kingdom (Glendinning 2017), Spain (Pena-Longobardo et al. 2016) and Italy.

In the first decade of the century, LTC policies in Italy were improved with respect to both the availability of public funds and the quality of services. Nevertheless, while there were substantial improvements compared to the past, the goal of achieving an appropriate level of LTC services to meet population needs was still far from reach. The general expectation was that the LTC system would continue to improve in the years to come but the onset of the economic crisis and related cost-containment policies, which widened the gap between care needs and available public funding, completely modified the scenario.

How did cost-containment polices affect the provision of LTC services at the local level in Italy? This question has been largely overlooked within the Italian debate, which up to now has concentrated exclusively on macrotrends such as expenditure levels and coverage rates. The lack of interest in the effects of cost-containment policies on welfare arrangements at the local level actually concerns not only Italy but also the wider context of comparative research on LTC, although with notable exceptions (Journal of Social Services Research 2016; Kroeger and Bagnato 2017). Internationally, the scarcity of analysis on the nexus between macro cost-containment policies and changes in care provision on the ground has been highlighted as a key stumbling block to our understanding of the transformation of LTC in times of austerity (Deusdad, Pace and Anttonen 2016: 147). Emphasising this point is the argument that focusing on the links between austerity-induced macro constraints and the re-framing of welfare systems locally represents 'the best strategy to understand current changes in welfare policies' (Ranci, Brandsen and Sabatinelli 2014: 274).

The analysis of the transformations that occurred in the provision of LTC services at the local level in Italy as a consequence of cost-containment policies is, therefore, uncharted territory. This article intends to explore this territory through the eyes of people who are particularly well placed to do so, i.e. services managers with long experience in the field. The qualitative methodology is particularly appropriate for such an exploratory goal 
because its intrinsic nature resides in 'a set of interpretative, material practices that make the world visible' (Denzin and Lincoln 2011:3).

\section{The interrupted development of the Italian LTC system}

\section{The enhancement of LTC services prior to the economic crisis}

Developed since the 1980s, the Italian public LTC system for older people comprises four separate policy programmes (see below) which are underpinned by three parallel silos of government activity: health care (which is the responsibility of the 20 regional governments), social care (under the remit of around 8,ooo municipalities) and attendance allowances (administered by the national government).

With respect to community care, the leading programme is 'integrated home care' (assistenza domiciliare integrata, ADI), which delivers mostly home visits by health care professionals (nurses, physiotherapists, etc.) aimed at providing medical, nursing and rehabilitation care at home, in principle integrated with forms of home help (but in reality this occurs only in a minority of cases). Services are provided free of charge according to need, overseen by the regional governments and supplied by local health authorities. The other programme of in-kind services provided in the community is home help (servizio di assistenza domiciliare, SAD), delivered by municipalities, which aim to provide support for personal care, home management and social integration. It is both needs-tested and means-tested, and a co-payment is often required. Institutional care is regulated by the Regions and is accessed only according to need. A (usually high) copayment is levied on the user and eventually his or her family, which is legally required to contribute with its own resources if the user is not able to pay. Most of the publicly funded care is provided by contracted-out providers: public providers receive 30 per cent of the overall LTC public expenditure for services in-kind, private not-for-profit providers receive $5^{\mathrm{O}}$ per cent and private for-profit providers receive 20 per cent (Allen at al. $2011)$.

The fourth pillar of LTC is an attendance allowance (indennità di accompagnamento, IA) which is a national monthly disability cash benefit of $€_{516}$ (in 2018), administered by the central government and provided to all people assessed (by a local committee) to be in a condition of full dependency, irrespective of the claimant's financial situation. IA is given to the dependent person, who can use it without any constraints, e.g. for the purchase of commercial services, to pass on to care-giving relatives or for any other purpose. 
In the first decade of this century, Italian public LTC policies for older people were enhanced in a number of ways. Firstly, expenditure grew continuously and coverage for most services expanded. Secondly, the quality of in-kind services increased in the context of wider investments and interest in older people's dependency and disability. These improvements took place - albeit within an overall policy context still facing several shortcomings - with different features and to various degrees across different areas of the country. Despite these local variations, it was a national trend (Chiatti et al. 2010).

It should be noted that, between 2000 and 2010 , the share of older people (i.e. those aged $6_{5}$ and over) receiving public home care services (ADI and $\mathrm{SAD}$ ) rose by around 70 per cent (taken together, from 3.7 to $5.7 \%$ ). However, even this increase in in-kind services was not able to match demand, mostly due to the extremely low intensity of the care provided (e.g. in ADI an average of just 20 hours of home care visits per user per year). Coverage of institutional care also rose during the decade, although to a lesser degree (from 2.0 to $2.4 \%$ of older people in nursing homes), influenced by the policy trend-consistent with most Organisation for Economic Co-operation and Development countries (Gori et al. 2015) - to assign priority and more resources to expanding community care. Turning to cash benefits, the attendance allowance (IA) strengthened its role as the most used measure for the support of older people and their families, rising from a coverage rate of 9.2 per cent of older beneficiaries in 2001 to 12.7 per cent in 2010 (Table 1). Various reasons - not discussed here ( see Gori 2012) - explain this trend, with the main one being that the IA is an entitlement for older dependent people that is not conditional on public budgetary resources being available, as is the case for services in-kind (Gori 2003).

The low availability of in-kind services and high rates of IA deeply influenced the way families managed care for their older members. In fact, these years were characterised by a dramatic increase in the private employment of care assistants, especially migrant care workers, by families to provide part- or full-time LTC to dependent older relatives. ${ }^{1}$ Overall, in 2010 Italy's total public LTC expenditure was around the European Union (EU) average, but the portion devoted to cash benefits was particularly high in comparative terms, amounting to some half of the total (European Commission 2012).

Since the beginning of the 20oos, the quality of in-kind services also had improved significantly. Many regional governments developed policies to enhance LTC quality, especially the management of the care process and the quality of institutional care. With respect to the former, various aspects contributed to the improvement. Firstly, access was strengthened 
T A B L E 1. Coverage rates for long-term care programmes in Italy, 2000 , $2 \mathrm{OIO}$ and $2 \mathrm{OI}_{3} / \mathrm{I}_{4}$

\begin{tabular}{lccc}
\hline & $2000^{2}$ & 2010 & $2013 / 14^{3}$ \\
\hline & & Percentages & \\
Institutional care & 2.0 & 2.4 & 1.9 \\
Community care - ADI & 1.9 & 4.2 & 4.2 \\
Community care - SAD & 1.8 & 1.5 & 1.2 \\
Attendance allowance - IA & 9.2 & 12.7 & 12.0 \\
\hline
\end{tabular}

Notes: 1 . Users as a percentage of the population aged $65+.2$. Data on servizio di assistenza domiciliare (SAD) refer to 2003 and data on indennità di accompagnamento (IA) to 2001 , as data for the year 2000 are not available. 3. These data are the most recent available at the time of writing. Data on IA and on institutional care refer to 2014 , data on community care refer to 2013.

Sources: Institutional care: Istat, I presidi residenziali socio-assistenziali e socio-sanitari, ISTAT, Rome, various years. ADI: Annuario del Servizio Sanitario Nazionale, Department of Health, Rome, various years. SAD: Interventi e servizi sociali dei Comuni singoli o associati, ISTAT, Rome, various years. IA: Inps database, www.inps.it.

through the establishment of an 'integrated point of access' at the local level, i.e. a single point of entry to the overall LTG system. Secondly, the initial needs assessment was further enhanced by establishing multi-professional geriatric evaluation units. These are in charge of delivering a comprehensive examination of users' conditions and their family's situation at the onset of the care process in order to design a tailored care plan. Thirdly, the follow-up of users and family carers' conditions over time was promoted through a set of actions and tools - like periodical re-assessments and case management - aimed at monitoring the situation to detect changes and consequently to modify the care plan if necessary (Chiatti et al. 2010).

\section{The economic crisis and austerity measures}

Towards the end of the decade, the overall picture was mixed. On the one hand, the Italian LTC system had substantially improved in comparison with the past, while, on the other hand, there was still a long way to go to reach an appropriate level of LTC services to meet the actual needs of the older population. The general expectation among practitioners, policy makers and experts was that LTC policies would continue to improve and be present in the policy agenda over the following years, in line with the previous trend. The appearance of the economic crisis, however, transformed this scenario.

In Italy, the economic crisis is defined approximately as the period affected by economic recession between 2007 - the last year when Gross Domestic Product (GDP) rose - and 2015 , the first year when GDP began 


\section{Cristiano Gori}

to rise again significantly. The main characteristics of the recession in Italy were a constant yearly reduction in GDP (ranging from $-0.1 \%$ in $2007-$ 2008 to $-6.3 \%$ in $2008-2009$ ), with a brief period of de facto zero-growth (between 2009 and 2011 ), and an increase in public debt as a percentage of GDP (from $100 \%$ in 2007 to $131 \%$ in 2015) (ISTAT 2016a). The crisis dramatically affected the economic conditions of the population: between 2007 and 2013 average disposable household income decreased by 13 per cent in real terms. In terms of length and intensity, such a fall in household income was the hardest since the Second World War (Brandolini 2014).

With respect to public finances, cost-containment and austerity policies were imposed as an overall priority for the public sector. This goal also affected LTC policies and the previous political aim to develop this branch of the welfare state further was put aside. Expenditure by municipalities devoted to dependent older people traditionally constituted a minor share of the total LTC budget but nevertheless it decreased further from $€_{1.4}$ to 1.1 billion between 2007 and 2013 (ISTAT 2017). The resources spent on LTC by the Regions, dedicated to ADI and institutional care, fell from $€_{7.7}$ to 7.0 billion during the period 2008-2015 (Ragioneria Generale dello Stato 2017). With respect to the IA, expenditure increased in the 200os, reaching $€ 9.4$ billion in 2010 (an increase of $€_{2.4}$ billion since 2005) and then slightly diminished (Ragioneria Generale dello Stato 2017). Consistent with the changes in the expenditure dedicated to LTC, around the turn of the decade the trends in the percentage of the older population receiving public care also changed. Coverage either started (institutional care and IA) or continued (SAD) to decline (Table 1). Overall, coverage in the ADI programme remained stable at 4.2 per cent, but national data have to be interpreted with particular caution: while ADI coverage fell during the period 2010-2013 in most of Italy, it grew substantially in the Southern part of the country, where it used to be extremely low. The increase was mostly due to EU funds allocated for this purpose. ${ }^{2}$ The overall changes in coverage rates mirrored what was happening generally in the LTC system, with previous improving trends being interrupted, for example, with respect to quality (see below).

Moreover, the reductions in public LTC expenditure contrasted with the continuous growth in the older population. In fact, the number of older people with severe functional limitations living in the community increased rapidly, from 2 million to 2.6 million people over the period 2000-2015, with most in the frailest age group, i.e. those aged 75 years and over $(2.05$ million people in 2015) (ISTAT 2016b). 


\section{Method}

\section{Sampling}

Managers employed in Italy's publicly funded LTC system for older people were selected for this study. They were contacted via the Network Non Autosufficienza (NNA), an Italian network of both care professionals and scholars. ${ }^{3}$ The sample was designed according to purposive criteria (Mason 2002) concerning both interviewees' professional profile and their placement in the care system. Managers with substantial experience of LTC service delivery were chosen (at the time of the interviews the mean was 20.4 years of experience and the minimum was 15 years). Inclusion criteria aimed to ensure that all relevant constituencies were covered in order to provide a comprehensive view of LTC services provision at the local level throughout the country. Therefore, the sample selection aimed to achieve a balanced mix between managers who: work in different geographical areas of the country (North, Centre, South); are in charge of home as well as residential care services; and are responsible for services directly run by the public sector and for services contracted out to private providers (non-profit and for-profit) (Table 2 ).

A number of reasons contributed to the decision to interview managers and not other stakeholders involved in LTC delivery, such as users or family members. Firstly, this study looks mainly at the effects of cost-containment policies on LTC provision, not on the conditions of older people and/ or their families. Therefore, the choice was made to interview managers who are specifically involved in supplying LTC services. Secondly, their role provides managers with a broad view of the LTC system at the local level. Thirdly, the managers' role imparts a particular understanding of the nexus between public funding constraints and service delivery. Combined, these two reasons underlay the rationale for selecting managers instead of care workers. Moreover, experienced managers were selected in order to guarantee in-depth knowledge of the sector and the ability to provide first-hand comparisons between the period of austerity measures and the developmental context that preceded it. Nevertheless, it is acknowledged that managers are just one of various stakeholders involved in LTC locally and their judgements and statements are, by definition, biased by their own role and responsibilities.

\section{Data collection}

Interviews were conducted by the author in the second semester of 2015 , at a time when cost-containment policies had been in place for several years. Interviews lasted between $5^{\mathrm{O}}$ and 75 minutes and were digitally recorded 
Т А в L E 2. Sample matrix: the profiles of managers interviewed

\begin{tabular}{|c|c|c|c|c|}
\hline $\begin{array}{l}\text { Interviewee's } \\
\text { number }\end{array}$ & $\begin{array}{l}\text { Geographical } \\
\text { area }\end{array}$ & $\begin{array}{l}\text { Services' } \\
\text { typology }\end{array}$ & Sector & $\begin{array}{l}\text { Years working } \\
\text { in LTC }\end{array}$ \\
\hline 1 & North & Home & Private contracted out & 15 \\
\hline 2 & South & Residential & Private contracted out & 18 \\
\hline 3 & South & Residential & Public & 17 \\
\hline 4 & North & Residential & Private contracted out & 16 \\
\hline 5 & North & Home & Public & 21 \\
\hline 6 & North & Residential & Private contracted out & 18 \\
\hline 7 & Centre & Residential & Public & 24 \\
\hline 8 & Centre & Home & Private contracted out & 16 \\
\hline 9 & South & Home & Public & 17 \\
\hline 10 & South & Home & Public & 18 \\
\hline 11 & North & Residential & Private contracted out & 27 \\
\hline 12 & Centre & Home & Public & 17 \\
\hline 13 & South & Residential & Private contracted out & 19 \\
\hline 14 & North & Home & Public & 25 \\
\hline 15 & Centre & Residential & Private contracted out & 24 \\
\hline 16 & South & Home & Public & 16 \\
\hline 17 & Centre & Residential & Private contracted out & 25 \\
\hline 18 & North & Residential & Private contracted out & 22 \\
\hline 19 & North & Home & Public & 24 \\
\hline 20 & North & Residential & Private contracted out & 22 \\
\hline 21 & Centre & Home & Private contracted out & 27 \\
\hline 22 & South & Residential & Private contracted out & 28 \\
\hline 23 & South & Home & Private contracted out & 19 \\
\hline 24 & Centre & Residential & Public & 21 \\
\hline 25 & North & Home & Public & 18 \\
\hline 26 & North & Home & Private contracted out & 16 \\
\hline 27 & South & Residential & Public & 23 \\
\hline 28 & South & Residential & Private contracted out & 24 \\
\hline 29 & Centre & Home & Private contracted out & 19 \\
\hline 30 & North & Residential & Public & 22 \\
\hline 31 & South & Home & Private contracted out & 26 \\
\hline 32 & North & Residential & Private contracted out & 17 \\
\hline 33 & Centre & Home & Public & 18 \\
\hline 34 & North & Home & Private contracted out & 15 \\
\hline Overall sample & $\begin{array}{l}14 \text { North, } 9 \\
\text { Centre, } 11 \\
\text { South }\end{array}$ & $\begin{array}{l}17 \text { home } \\
\text { care, } 17 \\
\text { residential } \\
\text { care }\end{array}$ & $\begin{array}{l}20 \text { private contracted } \\
\text { out, } 14 \text { public }\end{array}$ & $\begin{array}{c}\text { Mean = 20.4 } \\
\text { minimum }= \\
1_{5}\end{array}$ \\
\hline
\end{tabular}

with participants' permission. In order to saturate the sample, 43 managers were contacted and 34 agreed to be interviewed. The participating managers were assured of anonymity. The interviews were transcribed verbatim by a research assistant not involved in the research process. The study complies with ethical standards, including informed consent obtained from participants. 
The semi-structured interviews guideline was built around the three main dimensions of LTC services delivery: 'who' receives care, 'what' services are provided and 'how' their provision is arranged (Pavolini and Theobald 2015 ). For each dimension, several open-ended questions were asked concerning the following topics: coverage, eligibility criteria and co-payments ('who'), typology and quality of the services provided ('what'), care process arrangements, relationships between care services and older people's families, and relationships between public institutions commissioning services and contracted-out providers ('how'). For each topic, interviewees were asked to highlight what have been - in their opinion - the main changes that have occurred due to cost-containment policies within the LTC system in their local area, and the effects on older people, families, care workers and the overall LTC system. In addition, interviewees were asked to discuss the trends they highlighted.

\section{Data analysis}

The analysis was conducted following the framework analysis method, originally developed for qualitative analysis in applied social policy research (Ritchie and Spencer 1994; Ritchie and Lewis 2003; Spencer et al. 2013) and now used in a range of other fields, such as health policy (Gale et al. 2013). Following the usual steps of this method, the first phase began with familiarisation, i.e. reading the interview transcripts several times, noticing a number of points, impressions and issues. This was followed by the construction of an initial thematic framework, identifying various key themes (each organised into sub-themes) that came to the surface during the familiarisation process, which were used to group the content of the interviews. The following step implemented the grouping process, which had two parts: (a) indexing - labelling the various parts or sections of the data according to the theme they corresponded to; and then (b) sorting - each specific piece of data previously indexed was moved from its original textual context and placed into charts of themes and subthemes, according to the initial framework.

Once the material was organised into themes (and sub-themes) according to the provisional framework, the author consulted two colleagues, LTC scholars not involved in the project, for their feedback. This was a useful exercise for the reviewing stage, when all the material was read again, and some themes and sub-themes were modified. As a result, six cross-cutting thematic categories were identified that depict, according to the interviewees, the main transformations that occurred in the provision of LTC at the local level in Italy as a consequence of cost-containment policies. These categories are outlined in Table 3 and analysed in the next section. 
T A в L 3 . Categories

\begin{tabular}{ll}
\hline Category & \multicolumn{1}{c}{ Definition } \\
\hline 1. Uncertainty & $\begin{array}{c}\text { The inability to predict what direction the LTC system is going to } \\
\text { take in the foreseeable future } \\
\text { Pressure to focus excessively on day-to-day service delivery at the } \\
\text { expense of a medium- to long-term view of their future } \\
\text { The risk of not being able to maintain the level of quality of care } \\
\text { achieved so far } \\
\text { Tensions due to the increasing requirement to ration the provision } \\
\text { of public LTC services }\end{array}$ \\
4. Allocative tensions & $\begin{array}{l}\text { The very different impacts of the trend of re-familiarisation } \\
\text { depending on families' financial situation } \\
\text { 5. Unequal } \\
\text { re-familiarisation } \\
\text { tions that are not appropriate to meet their needs }\end{array}$
\end{tabular}

\section{Results}

\section{Category I: Uncertainty}

Uncertainty about the future of the LTC system represents the category that recurred the most throughout the interviews, with managers referring to this concept when commenting on a number of different topics. The theme was raised in the context of the level of public funding for LTC and, in a wider sense, the priority that politicians would give to the sector in the years to come. This category, therefore, summarises interviewees' overall mood with regard to LTC policies in Italy.

To appreciate its relevance it is necessary to assume an inter-temporal view, linking the objective trends within the sector to the stakeholders' subjective responses to these trends (Meagher, Szebehely and Mears 2016). The current LTC system began to develop in the 1980 os and the coverage rate increased steadily. The difference between decades was not in the trend but in its speed: development was slower in the 1980s, quicker in the 1990s and at its most rapid in the 2000s (Chiatti et al. 2010). In parallel, the coverage rate followed the same growth trajectory as the whole public LTC system. This long-term trend shaped professionals' expectations about LTC policies. They expected annual improvements to the system, not only in terms of coverage but also in terms of resources and quality. Improvements actually took place and led practitioners to confidently expect a positive scenario in the years to come. As these experiences were repeated, they produced new rising expectations over time. Therefore, even if the welfare system for in-kind services continued to suffer from several deficiencies, the professionals involved had positive and self-fostering expectations about the future. This occurred to different degrees and 
in various versions throughout most of the country, peaking in the 2000 . Then, after the turn of the decade, the public LTC system had to address several difficulties.

Interviews reveal the impact of this change of context on managers' attitudes.4 Following the deep transformation of the scenario, the common view of the future of the LTC system shifted from a long-term attitude of rising expectations to a widespread feeling of uncertainty. The latter has become the prevalent attitude among most of the interviewed stakeholders: they think that it is simply impossible to predict what direction the Italian LTC system is going to take in the foreseeable future, whether it be further development, retrenchment or anything else. The uncertainty about the future is accompanied by disorientation due to the utterly unexpected, and quite rapid, modification of the LTC landscape.

Up to a few years ago I was sure: Italians are ageing quickly and LTC services would continue to expand. Now I have no clue about what is going to happen. (I 3)

I would never have expected to witness a retrenchment of the system. I have always been used to improvements - sometimes bigger, sometimes smaller - and I was sure that was the direction ... In the 2000 s there was so much emphasis on the need to strengthen LTC ... it looked like the obvious direction. After what has happened in recent years, I am really confused about the future. (I 17 )

\section{Category 2: Short-termism}

Along with uncertainty, the other frequently recurring category in the interviews is short-termism. This category is defined as the pressure managers experience in being forced to focus excessively on day-to-day service delivery at the expense of taking a medium- to long-term view.

These days we are so absorbed by a number of always new, and urgent, matters arising continuously that thinking beyond tomorrow is almost impossible. (I 8)

Managers represent short-termism as a broad trend influencing the range of activities they are in charge of, i.e. it is the main 'logic' affecting their own operational approach and that of their staff. When asked about specific examples, they tend to focus on the following three. First of all, they state that the current situation hinders their ability to innovate services in order to address the transformations in the profile and needs of the older population. The predominance of short-termism, in order words, restricts the possibilities of modifying the current ways of providing services and designing, and testing, new ones. The most common example concerns the delays in designing and implementing services dedicated to the growing number of older people with dementia. Furthermore, managers 


\section{Cristiano Gori}

signal a disinvestment in interventions aimed at maintaining, updating and improving care workers' skills. Interviewees, in fact, report sharp decreases in the provision of continuous education and training for care workers. Finally, managers in charge of residential homes highlight a drop in the capital investment necessary to maintain and/or to upgrade the institutions, a trend that is also noted in other countries (Janssen, Jongen and SchroderBack 2016). In fact, many providers increasingly cannot afford to make the economic investment necessary to renovate buildings, furniture and all the various care instruments that are needed.

Having mentioned some examples, we must reiterate the comprehensive nature of short-termism. This category can be interpreted as a broad overarching link between the macro-trends affecting the LTC system and the specific transformations that have occurred at the local level, which are investigated through the other categories presented below. The nature of this link comes to light in the interviews: when asked about the causes of short-termism, managers mostly refer to the macro-trends previously identified, i.e. the widening gap between care needs and resources, and the uncertainty about future political choices. In fact, they say that their energy, attention and thoughts are absorbed by the difficulties of providing services with the (constrained) resources available.

You know, I spend the whole day looking for solutions to maintain proper service provision with the funds we have. Not that much time for anything else, really. (I 22 )

In parallel, they state that it is extremely difficult to plan for the future because they do not know what amount of public funds is going to be devoted to LTC and, more generally, they cannot predict the level of political interest that there will be in the sector in the years to come.

How can we plan for the future? We don't know how many resources the government is going to devote to LTC in the coming years ... Actually, we don't know if the government wants to invest in the sector. (I 19)

\section{Category 3: Endangering quality}

When asked about quality, interviewees refer primarily to residential care, the setting where, in comparison with community care, quality policies are more developed. This is also a common trait across other developed countries (Mor, Leone and Maresso 2014). Even though quality standards in residential care were significantly improved during the previous decade by regional governments, further steps are needed-an assessment confirmed by various studies (e.g. NNA 2015). The shared expectation among stakeholders was that quality would continue to improve but, following the advent of the economic crisis, the scenario has changed radically. In 
fact, further improvements in quality are now off the agenda in most regions and interviewed managers express their concerns about being able to meet the standards reached so far.

Our residential home is required to meet a number of precise standards concerning the presence of care professionals, their profile and education, and the number of minutes each week they devote to each older person, and board and lodging too. But the reality is that the current level of public funding is not in line with the level of quality we are supposed to deliver. (I 9)

Thus, a mismatch between the funds available and current quality standards is signalled. This is explained by the timing of when quality standards were introduced. In fact, the interviewees argue that these standards were devised at a time when public funding was expected to keep on increasing, whereas this is no longer the case.

The real problem is that the standards were introduced when the context was utterly different and everyone was sure we would have the funds to maintain those standards in the future. (I 14)

It is not surprising, therefore, to find that some providers, while officially stating that they meet the legal quality standards, are actually finding alternative ways around them in order to contain costs. This is, for obvious reasons, a phenomenon that is extremely difficult to monitor but our respondents agree that such practices are growing. An apparent proof of this trend consists in the increasing involvement of people who are not nursing home staff members carrying out care tasks within residential settings. The most cited example is the growing presence of people chosen by users' families - either relatives or private care workers that they employ - to help residents who are unable to eat autonomously at meal times. Furthermore, there are signs of the increasing involvement of volunteers in other activities that previously were carried out by residential care staff. The situation described leads us to ask a direct question, regarding both the present and future:

Can we afford this level of quality? (I 27)

Families' responses to the current situation complete a complex picture. According to the interviewees, an increasing number of relatives report being dissatisfied with the care received by older people living in institutions. The presence of a certain portion of dissatisfied families is not a new phenomenon: the newness is their rising numbers and their behaviour. Managers state that dissatisfaction with quality leads families to engage with residential home staff in a much more aggressive and conflictual manner than used to be case in the past. 


\section{Cristiano Gori}

More and more families are unhappy with the way their older relatives are cared for. They ask for more and they do it in such an aggressive way. Up to a few years ago, families used to express their dissatisfaction in a less aggressive way ... It looks like they think that the more aggressively they behave the better care their dear ones are going to receive. (I 32 )

Assembling the evidence gathered on quality issues highlights a major dilemma: while many families judge the current quality of residential care to be inadequate, at the same time most mangers declare that it is extremely difficult to maintain. Up to now, the only strategy used to raise quality has been to surpass the standards set by regional governments for those who are ready to pay for it. This is done by linking better quality services either care or board and lodging-to an increase in the usual fees charged. Managers state that this option is increasingly applied, a trend confirmed by other available evidence (Montemurro and Petrella 2016).

\section{Category 4: Allocative tensions}

Increasing tensions are widely reported regarding allocative choices for services in kind. Locally elected politicians hold the main responsibility in this area, with substantial discretionary power. In fact, while the eligibility criteria for cash benefits (attendance allowance, IA) are set nationally and those meeting these criteria are entitled to it, eligibility criteria for in-kind services are defined locally, in the absence of any legal arrangements assuring older people the right to receive these services. Although under these institutional arrangements local politicians have always been required to set their own priorities, it is obviously a completely different scenario to do so when the public budget is growing as opposed to making such decisions in the context of decreasing funds and rising care needs. Interviewees' remarks on resource allocation mainly focus on community care.

According to the interviewees, at the onset of the crisis politicians decided to concentrate available economic and human resources into safeguarding the provision of care inputs - i.e. on the number of users and hours of home care - at the expense of the care process. As mentioned above, during the previous decade substantial investments were made throughout Italy to improve the management of the latter, a trend common in many other European countries (Genet et al. 2013). However, once the economic crisis began, decision-makers started to disinvest in the care process and in many areas - it actually worsened. The interviews signal this trend through a wide range of examples, such as reductions in opening hours of integrated points of access, drops in the number of staff devoted to assessment units and decreases in training aimed at improving how the integrated points of access function. 
Nowadays the assessment units do not design a proper care-plan; in most cases these units exclusively distribute the services available among older people ... Years ago, various efforts were made to improve the care-planning function, and some improvements actually took place. However, at the beginning of the economic crisis staff was reduced and their performance began to worsen. (I 16 )

As the disinvestment in the care process - confirmed by other studies (Gori et al. 2014) - did not suffice to address budget constraints, local politicians had to face further uncomfortable allocative dilemmas. The next step consisted, inevitably, of taking care provision into account and deciding on whether to prioritise the number of users (coverage) or the number of care hours per user (intensity). Politicians have chosen to decrease intensity in order to protect coverage, as indicated by both interviewees and other quantitative evidence (Montemurro and Petrella 2016). Even though this preference has not been enough to avoid a decrease in coverage, it was $d e$ facto aimed at minimising the decline. Overall, the findings presented here depict clearly political decision-makers' ranking of allocative priorities in community care: first (by far), coverage; second, intensity; and third, the care process.

A difference in priorities among managers and politicians comes to light. Qualitative data show that politicians' preference to maintain LTC coverage is particularly intense: according to the interviewees, local decision-makers think that reductions in coverage come at a very high cost in terms of maintaining political consensus whereas there is much less blame to bear in cases where care processes worsen or intensity of services is reduced. The purpose of protecting coverage is painted as an 'obsession' and described in particularly vivid terms.

There is a simple rule. Politicians are really scared by the prospect of local papers stating that they are reducing the number of older people receiving assistance and they do everything they can to avoid it. (I 25)

I am not surprised by politicians' obsession with coverage. More public services users, more votes. That's it. (I 18)

LTC service managers make it clear that their view is different. They do not think coverage should always be the absolute priority; they maintain that the features of care packages, such as the number of hours provided and care processes, should be taken into account in allocative choices. In their opinion, it would make sense to relinquish some degree of coverage in order to provide adequate care to those receiving it. Managers, therefore, depict a contrast between 'their' (politicians') focus entirely on user numbers and 'our' (professional community's) focus, providing a more comprehensive view on care.

Politicians are completely interested in coverage. I wonder, instead, what's the point in providing services to as many older people as possible if it means not caring for 


\section{Cristiano Gori}

them properly. I don't think the number of older people cared for is a value in itself; the care that is actually provided is what matters. ( $\mathrm{I}_{5}$ )

\section{Category 5: Unequal re-familiarisation}

Historically, the Italian care model has been characterised as being overwhelmingly reliant on families, also in the light of the wide utilisation of cash benefits (Anttonen and Sipila 1996; Da Roit 2007). Although developments in the 2ooos aimed to modify this scenario, at least to some degree, the interviewees underline that recent cost-containment policies have determined a move backwards. A similar trend of reinforcing families' caring responsibilities also has occurred in other countries where austerity measures were implemented, and is usually labelled as a process of 're-familiarisation', with the burden of care falling disproportionately on female members (e.g. Deusdad, Pace and Anttonen 2016). However, in order to capture the peculiarities of the recent Italian context, we introduce the more specific category of 'unequal re-familiarisation', which refers to the extremely differentiated impacts that this trend has had depending on families' economic situation. Up until now, this factor has been quite overlooked in comparative research on care for older people but it is important to insert it into the picture in order to capture the (increasing) role of social class inequalities and their interaction with policy arrangements (Saraceno 2010). The relevance of 'unequal re-familiarisation' emerges distinctly in managers' statements: while they do not take the increasing pressure on families into account per se, they strongly differentiate the effects of cost-containment policies according to families' economic situation.

Care of older people is increasingly a family matter, with a huge discrimination between the well off and the worst off. (I 27)

Being a dependent older person represents a high factor of risk that can find positive responses with the presence of two elements: good economic resources and a quality family network. But the latter alone does not suffice and the former increasingly makes a difference. (I 24)

A widely reported result of 'unequal re-familiarisation' derives from the interaction between rising residential care fees, reduced exemptions from such fees and a worsening of families' economic situation. In recent years, in response to the lack of adequate public funding, many institutions have increased their fees and narrowed the eligibility criteria for exemption, based on a means-test of the older person and their family. Although these decisions are made locally, this has been a common trend throughout the country (Pesaresi 2016). At the same time, the economic situation of 
many families has worsened. The interviewees underline that this mix of factors has led to a common outcome: increasingly, families do not put their older relatives into residential care because they cannot afford it. Various alternative care arrangements are organised, sometimes hiring a migrant care worker through illegal arrangements, which is usually a cheaper option than residential care (Pavolini, Ranci and Lamura 2017). Whatever the actual arrangements in place, what strikes the interviewees is that giving up on residential care occurs even in cases of extremely dependent older people, for whom any other care arrangement based in the home is not appropriate.

More and more families are dismissing the residential care option because they cannot afford fees ... I mean also families with extremely dependent older relatives. I really don't know how they can manage the care at home. (I 4 )

In many Italian municipalities, eligibility criteria to receive home help (SAD), a means-tested service, have been modified in line with the changes introduced in residential care. In fact, these criteria have been narrowed so that in order to qualify for home help older people's economic situation now has to be worse than previously used to be the case (Longoni 2014). According to the interviewees, trends in both home help and residential care consistently contribute to the emergence of a new social profile: an increasing number of older people's families are 'neither poor enough nor rich enough' to obtain care for their dependent older relatives from external sources. In fact, their economic resources are not scarce enough to be exempted from residential care fees that they cannot afford nor are they eligible to receive SAD. Thus, their dependent relatives are left out of public services. At the same time, however, these families are not well off enough to buy proper care in the private market. These families, therefore, are trapped in this 'no-man's land' that forces them to rely entirely upon their own informal care resources. The interviewed managers report that this phenomenon is relatively new and that the number of families in this uncomfortable situation is rising rapidly.

I see more and more families that are neither poor enough to receive public care services nor rich enough to buy these services in the private market. At the end of the day, they rely exclusively on their own members to care for their dependent relatives. (I 12 )

\section{Category 6: Inappropriate care}

Managers underline that austerity measures have increased the group of older people receiving public care interventions that are actually not appropriate to meet their needs. It is a widely perceived trend: among the copious 


\section{Cristiano Gori}

examples made to illustrate it, three critical situations are most commonly cited. Unsurprisingly, the latter are strictly interrelated to the other categories we have previously discussed. In fact, according to the interviewees, the various effects of cost-containment policies converge towards producing inappropriate solutions for LTC users; or, to put it differently, the (lack of) appropriateness represents a different angle to look at the other categories previously discussed. The most signalled critical situations concern the care setting, the care package and the care model, respectively.

The first situation, regarding the care setting, refers to dependent citizens who continue to live in the community even though their condition is too severe to do so safely, and they should be admitted to a residential facility. Remaining in an inappropriate setting is mostly due to the fact that eligibility criteria to enter residential care, based on needs, have been raised (Pesaresi 2016). As mentioned above, this has been done to manage the gap between the increasing demand for residential care and the decreasing supply. The increase in fees ( see category 5 above) also has contributed to this problem. While these older citizens usually receive community care services, this response does not meet their needs adequately.

Nowadays there are older people who are extremely physically dependent or strongly suffering from dementia whose needs are assessed as not being severe enough to enter residential care. They live at home and receive home care, but they would need the kind of 24 -hour professional support available only in institutions. I don't see how their families can cope. (I 20)

Another widely reported situation of inappropriateness concerns the care package provided to users living at home. An increasing number of older people with complex needs receive home care that the interviewees judge to be of inadequate intensity, in terms of the number of hours of care provided per week. According to service managers, these users could be effectively cared for at home with an appropriate care package, but they do not obtain it. This point connects to the interviewees' critical assessment of politicians' preference to prioritise coverage (as discussed in category 4 ).

We have many older people with severe dependency living at home who receive too few hours of home care. These are not people for residential care, these are people that need a proper package of home care but do not receive it. (I 2)

Finally, the implicit assumptions of the Italian culture of care-affecting LTC policy design at its roots (Pfau-Effinger 2005) - are called into question, with reference to a small, but increasing, number of older people living in residential care even if they could be cared for in the community. They do not have family carers they can rely upon and, therefore, due to the shortage of intensive care at home, they cannot live in the community. Interviewees state that their situation conflicts with the country's traditional 
community care approach, which implies the presence of family carers. Furthermore, interviewees note that this group of people is going to grow in the future and that the Italian LTC system should be modified accordingly. But in times of uncertainty and short-termism (see categories 1 and 2 ), any revision of the system to improve it seems unlikely.

The problem is that our community care implies the presence of family carers ... but some older people do not have family carers, and they are going to increase. The system should be modified consistently with the transformation of society. But I do not see anyone interested in such an enterprise at the moment. (I 30)

\section{Discussion and conclusions}

This article has presented an explorative investigation of the effects of costcontainment policies on the provision of LTC services for dependent older people at the local level in Italy. This concluding section looks at the overall trends that are emerging, as well as the various implications for different stakeholders.

\section{LTC policy trends}

The view from the field, provided by services managers, depicts a system squeezed between a push back to the past and extreme difficulty in planning for the future. On the one hand, the data for Italy confirm a trend already noticed internationally: austerity measures 'are pushing countries back to a situation they were in at least two decades ago' (Schwartz 2013: 409). While Italy's LTC system is actually much more developed than it was two decades ago, cost-containment policies make it impossible or extremely hard to maintain the quantitative/qualitative levels of care achieved during the earlier era of expansion. In fact, they are pushing the system back to its previous traits. This trend is demonstrated, among other things, by the decrease in LTC population coverage, disinvestment in the care process and the difficulties in assuring the current standards of quality (see category 3 ).

On the other hand, the evidence gathered proves that an interpretation of austerity exclusively in terms of decreasing public funds would be too narrow. In fact, deep uncertainty over the future direction of LTC policies discussed in category 1 -and the permanent difficulties in providing services with the resources available lead the various stakeholders involved to exercise 'short-termism' (category 2). In turn, such an excessive focus on day-to-day service delivery prevents them from modifying the system to address the transformation of older people's needs and those of society. It is worth noting this trend as the Italian LTC system - although 


\section{Cristiano Gori}

improved - was still suffering from several shortcomings at the beginning of the crisis, as underlined by the comparison with other European countries (Bettio and Verashchagina 2012: $83-8$ ). Not by chance, two of the main examples highlighted in the interviews are the delays in designing appropriate solutions to meet the needs of the fastest growing group of dependent older people in recent years (people with dementia), and the particularly challenging reliance on informal networks of carers, reflecting the increasing number of older people without family members to count on. Looking towards the future, the delay in adjusting the LTC system to current exigencies is a legacy of austerity that cannot be underestimated because 'if today's decisions are merely responses to a pressing situation, tomorrow's care may have unanticipated consequences' (Thorslund, Bergmark and Parker 1997: 203).

\section{Some implications for stakeholders}

The evidence gathered highlights several implications of the transformation of LTC provision at the local level for the various stakeholders involved: users, care workers, families and political decision-makers. According to the interviewees, austerity measures have increased the number of beneficiaries receiving care that is not appropriate to meet their needs (as described by category 6). The latter is deeply associated with all the other categories presented in the analysis, and provides a particular insight into the changes that have occurred in the field. In fact, the various consequences of austerity have contributed to modifying the LTC system in such a way that inappropriate interventions have increased. Therefore, the growth in inappropriate care represents a particular fil rouge linking the various phenomena examined here.

In addition, another specific and cross-cutting fil rouge emerges with respect to care professionals: this theme concerns the quality of LTC work. The appearance of austerity has made local welfare facilities much more stressful to work in and the relationship between care professionals and users' families is much more complicated than used to be the case. The data show that services managers are disoriented by the deep, and unexpected, modification of the workplace context, and by the utter uncertainty about the future. They spend their working days attempting to maintain proper services provision with decreasing funds. At the same time, the evidence from residential care highlights the deterioration of the relationships between care staff and families. An increasing number of families, in fact, express their dissatisfaction with the care received by their older relatives and interact with residential care staff in a much more aggressive and conflictual manner than previously. 
Families' economic situation constitutes another key reference point to understand the data presented. The findings, in fact, prove that it is impossible to understand the trends of re-familiarisation due to austerity measures without taking into account the differences in families' and older people's economic conditions. This theme emerges not only in category 5 , devoted to 'unequal re-familiarisation', but also with respect to the growing strategy of addressing demands for better quality services in residential care through asking those who can afford it to pay additional fees. The nexus between LTC arrangements and families' economic conditions is receiving increasing interest in the comparative debate at the European level, from various analytical perspectives (Muir 2017; Rodrigues, Ilinca and Schimdt 2017), and it is definitely a key issue for the future.

Furthermore, the evidence brings to light the detrimental interplay between the modifications in policy arrangements' and of families' economic conditions. In order to save money, policy makers have introduced various changes to co-payments and eligibility criteria - raising fees in residential care, decreasing exemptions from such fees and narrowing means-testing in home help - that would have, in 'normal' times, reduced the number of families able to access public services because of their economic situation. But times of austerity are not 'normal' at all and, therefore, the worsening of families' economic conditions has made the impact of these changes particularly broad. To summarise, the modifications introduced have restricted access to services in kind at a time when families' worsening economic situation have increased pressures to enlarge access.

The interplay between policy changes and modification of families' economic conditions has led to the emergence of a new social profile, i.e. the increasing number of families neither 'poor enough' to obtain public services in kind nor 'rich enough' to buy proper care in the private market, and therefore trapped in a 'no-man's land'. This situation is not new internationally and, most notably, it has long been a peculiar trait of the LTC system in the United States of America (e.g. Frank 2012).

This study has also scrutinised the resource allocation tensions faced by political decision makers in times of austerity (see category 4 ). The phenomenon reported for Italy has also been observed at the European level, in terms of 'an emerging trade-off between quantity and quality ... that is, the increase or maintenance of the present coverage extensions is in contrast with increase or maintenance of the present level of intensity or quality of care services' (Leon, Ranci and Rostgaard 2014: 43). Although the data gathered concern allocative dilemmas in community care, tensions of no smaller relevance affect institutions (e.g. Pesaresi 2016). With respect to residential care, some international evidence indicates that in various European countries-including Italy-choices have been opposite to 
those made in community care, prioritising intensity over coverage; but here it should be borne in mind that people in residential homes tend to be much older and need much more care than in the past (Gianino et al. $2017)$.

The findings bring to light the attitudes towards allocative tensions of the different stakeholders involved in LTC delivery. In fact, the managers interviewed stress the different preferences between care professionals, including themselves, and politicians. The latter strongly prioritise coverage whereas the former think that more relevance should be assigned to the adequacy of the care package. Actually the balance between coverage and intensity in community care has been long discussed internationally and remains a controversial issue, with a number of arguments raised to support each of the two options, such as the preventive function of more coverage and the role of intensity in tackling the risk of institutionalisation (e.g. Genet et al. 2013). In a way, different priorities also seem to reflect the various stakeholders' positions in the LTC system. In fact, professionals focus mostly on single cases (a position consistent with the priority they assign to the adequacy of the care package provided to each individual) whereas politicians focus on the overall population (a position consistent with their preference for an increase in coverage).

Both the thematic categories identified and the implications derived here are relevant not only for Italy but also - to various degrees - for other European countries experiencing a widening gap between care needs and available public funding. This article, therefore, can be considered a contribution to the building of that 'European wide view on the implications of the economic crisis for care policy developments' that - up to now - 'has been missing' (Kroeger and Bagnato 2017: 202). Such a view is badly needed in order to understand the reality and the perspectives of LTC policies in Europe.

\section{Acknowledgements}

The author would like to thank Francesco Barbabella (Linnaeus University, Sweden and Inrca, Italy) and Giselda Rusmini (NNA, Italy) for their feedback on the provisional thematic framework designed from the initial analysis of the evidence gathered.

\section{NOTES}

1 It is estimated that over 830,000 care assistants are privately hired on formal or informal contracts by older people and their families (Pasquinelli 2013). 
2 Southern regions benefited from funds under the EU's Cohesion Fund 20072013 in order to develop ADI. In fact, in the Southern regions the average percentage of older users doubled between 2007 and 2013 (from 1.7 to $3.4 \%$ ), whereas in the Centre and Northern Regions the rate decreased from 2010 to 2013 (from 5.4 to $5.0 \%$ ).

3 NNA, set up in 2009, produces a biennial report on the state of LTC policies in Italy (e.g. NNA 2015) and organises seminars and conferences. The managers interviewed were selected from a list of care professionals that had previously attended seminars and/or conferences organised by NNA.

4 As previously mentioned, the managers interviewed have been working in the LTC sector for a long time ( mean $=20.4$ years $)$.

\section{References}

Allen, K., Bednárik, R., Campbell, L., Dietrich, A., Hirsch Durrett, E., Emilsson, T., Glasby, J., Gobet, P., Kagialaris, G., Klavus, J., Kümpers, S., Leichsenring, K., Ljunggren, G., Mastroyiannaki, T., Meriläinen, S., Naiditch, M., Nies, H., Repetti, M., Repkova, K., Rodrigues, R., Stiehr, K., van der Veen, R., Wagner, L. and Weigl, B. 2011. Governance and finance of long-term care across Europe. Overview report. INTERLINKS report, University of Birmingham and HSMC/ European Centre for Social Welfare Policy and Research, Birmingham, UK and Vienna.

Anttonen, A. and Sipila, J. 1996. European social care services: it is possible to identify models? Journal of European Social Policy, 6, 2, 87-100.

Bettio, F. and Plantenga, J. 2004. Comparing care regimes in Europe. Feminist Economics, 10, $1,85^{-113 .}$

Bettio, F. and Verashchagina, A. 201 2. Long-term Care for the Elderly. Provisions and Providers in 33 European Countries. European Commission, Brussels.

Brandolini, A. 2014. I bilanci delle famiglie italiane dopo la grande recessione. In Fusaro, C. and Kreppel, A. (eds), Politica in Italia. I Fatti dell'Anno e le Interpretazioni. Edizione 20 I4. Il Mulino, Bologna, Italy, 208-37.

Chiatti, C., Barbabella, F., Lamura, G. and Gori, C. 2010. La 'bussola' di NNA: lo stato dell'arte basato sui dati. In Network Non Autosufficienza (ed.), L'Assistenza agli Anziani non Autosufficienti in Italia. $2^{\circ}$ Rapporto. Maggioli, Rimini, Italy, 13-39.

Da Roit, B. 2007. Changing intergenerational solidarities within families in a Mediterranean welfare state: elderly care in Italy. Current Sociology, 55, 2, 251-69.

Denzin, N. K. and Lincoln, Y.S. 2011. The Sage Handbook of Qualitative Research. Fourth edition, Sage, London.

Deusdad, B. A., Pace, C. and Anttonen, A. 2016. Facing the challenges in the development of long-term care for older people in Europe in the context of an economic crisis. Journal of Social Service Research, 42, 2, 144-50.

European Commission 2012. Long-term care: need, use and expenditure in the EU 27. Economic Paper 469, European Commission, Brussels.

Frank, R. G. 2012 . Long-term care financing in the United States: sources and institutions. Applied Economic Perspectives and Policies, 34, 2, 333-45.

Gale, N. K, Heath, G., Cameron, E., Rashid, S. and Redwood, S. 2013. Using the framework method for the analysis of qualitative data in multi-disciplinary health research. BMC Medical Research Methodology, 13, 117.

Genet, N., Boerma, W., Kroneman, M., Hutchinson and Saltman, R. B. 2013. Home Care Across Europe. Nivel, Utrecht, The Netherlands. 


\section{Cristiano Gori}

Gianino, M. M., Lenzi, J., Martorana, M., Bonaudo, M., Fantini, M. P., Siliquini, R., Ricciardi, W. and Damiani, G. 201 7. Trajectories of long-term care in 28 EU countries: evidence from a time series analysis. European Journal of Public Health, 27, 6, $94^{8-54}$.

Glendinning, C. 2017. Long-term care and austerity in the UK: a growing crisis. In Greeve, B. (ed.), Long-term Care for the Elderly in Europe. Routledge, New York, $107-25$.

Gori, C. 2003. Applicare i livelli essenziali nel sociale. Prospettive Sociali e Sanitarie, 15, $7,1-8$.

Gori, C. 2012 . Home care in Italy: a system on the move, in the opposite direction to what we expected. Health and Social Care in the Community, 2o, 3, 255-64.

Gori, C., Barbabella, F., Campbell, J., Ikegami, N., D’Amico, F., Holder, H., Ishibashi, T., Johansson, L., Komisar and Theobald, H. 2015. How different countries allocate LTC resources to older users: changes over time. In Gori, C., Fernandez, J. L. and Wittenberg, R. (eds), Long-term Care Reforms in OECD Countries. Policy Press, Bristol, UK, 77-1 15 .

Gori, C., Fernandez, J. L. and Wittenberg, R. (eds) 2015. Long-term Care Reforms in OECD Countries. Policy Press, Bristol, UK.

Gori, C., Ghetti, V., Rusmini, G. and Tidoli, R. 2014. Il Welfare Sociale in Italia. Carocci, Rome.

Greve, B. 2017 a. Some concluding reflections. In Greve, B. (ed.), Long-term Care for the Elderly in Europe. Routledge, New York, $185^{-93}$.

Greve, B. $2017 b$. Long-term care in Denmark, with an eye to the other Nordic welfare states. In Greeve, B. (ed.), Long-term Care for the Elderly in Europe. Routledge, New York, 168-84.

ISTAT 2016a. ISTAT. Datawarehouse. ISTAT, Rome. Available online at www.dati. istat.it [Accessed 5 May 2017 ].

ISTAT 2016b. Disabilità in Cifre. Datawarehouse. ISTAT, Rome. Available online at http://dati.disabilitaincifre.it/dawinciMD.jsp [Accessed 20 May 2017].

ISTAT 2017. I Servizi ed Interventi Sociali dei Comuni-Anno 2or 3. ISTAT, Rome.

Janssen, D., Jongen, W. and Schroder-Back, P. 2016. Exploring the impact of austerity-driven policy reforms on the quality of long-term care provision for older people in Belgium and the Netherlands. Journal of Aging Studies, 38, 1, 92-104.

Journal of Social Services Research 2016. Facing the challenges in the development of long-term care for older people in Europe in the context of an economic crisis. Journal of Social Services Research, 42, 2 (special issue).

Kroeger, T. and Bagnato, A. 201 7. Care for older people in early twenty-first-century Europe: dimensions and directions of change. In Martinelli, F., Antronen, A. and Mätzke, M. (eds), Social Services Disrupted. Changes, Challenges and Policy Implications for Europe in Times of Austerity. Edward Elgar, Cheltenham, UK, 201-18.

Leon, M., Ranci, C. and Rostgaard, T. 2014. Pressures towards and within universalism: conceptualising change in care policy and discourse. In Leon, M. (ed.), The Transformation of Care in European Societies. Palgrave Macmillan, New York, 34-61.

Longoni, B. 2014. I Servizi Domicilari. Maggioli, Rimini, Italy.

Maarse, J. A. M. and Jeurissen, P. P. 2016. The policy and politics of the 2015 LongTerm Care reform in The Netherlands. Health Policy, 1 2o, 3, 241-5.

Mason, J. 2002. Qualitative Researching. Second edition, Sage, London.

Meagher, G., Szebehely, M. and Mears, J. 2016. How institutions matter for job characteristics, quality and experiences: a comparison of home care work for older people in Australia and Sweden. Work, Employment and Society, 3o, 1, 1-19.

Montemurro, F. and Petrella, C. (eds) 2016. Le Politiche per gli Anziani non Autosufficienti nelle Regioni Italiane. Spi-CGIL, Rome. 
Mor, V., Leone, T. and Maresso, A. (eds) 2014. Regulating Long-term Care Quality. An International Comparison. Cambridge University Press, Cambridge.

Muir, T. 2017. Measuring social protection for long-term care. OECD Health Working Paper 93, Organisation for Economic Co-operation and Development, Paris.

Nadash, P., Doty, P. and von Schwanenflugel, M. 2017. The German Long-Term Care Insurance Program: evolution and recent developments. The Gerontologist. Published online 4 April, doi:10.1093/geront/gnxo 8.

Network Non Autosufficienza (NNA) (ed.) (2015). L'assistenza agli Anziani non Autosufficienti in Italia. Quinto Rapporto-Un Futuro da Ricostruire. Maggioli, Rimini, Italy.

Pasquinelli, S. 2013. Le badanti in Italia: quante sono, chi sono, cosa fanno. In Pasquinelli, S. and Rusmini, G. (eds), Badare non Basta. Il Lavoro di Cura: Attori, Progetti, Politiche. Ediesse, Rome, $4^{1-55}$.

Pavolini, E., Ranci, C. and Lamura, G. 2017 . Long-term care in Italy. In Greeve, B. (ed.), Long-term Care for the Elderly in Europe. Routledge, New York, 75-92.

Pavolini, E. and Theobald, H. 2015. Long-term care policies. In Kuhlmann, I., Blank, R. H., Bourgeault, I. L. and Wendt, C. (eds), The Palgrave International Handbook of Healthcare Policy and Governance. Palgrave, New York, 462-78.

Pena-Longobardo, L. M., Olivia-Moreno, J., Garcia-Armesto, S. and HernandezQuevado, C. 2016. The Spanish long-term care system in transition: ten years since the 2006 Dependency Act. Health Policy, 120, 10, $1177-82$.

Pesaresi, F. 2016. Quanto Costa l'RSA? Maggioli, Rimini, Italy.

Pfau-Effinger, B. 2005. Welfare state policies and the development of care arrangements. European Societies, 7, 2, 321-47.

Ragioneria Generale dello Stato 201 7. Le tendenze di medio-lungo periodo del sistema pensionistico e socio-sanitario. Report 18, Ragioneria Generale dello Stato, Rome.

Ranci, C., Brandsen, T. and Sabatinelli, S. 2014. Local welfare systems in Europe in the age of austerity. In Ranci, C., Brandsen, T. and Sabatinelli, S. (eds), Social Vulnerability in European Cities. The Role of Local Welfare in Time of Crisis. Palgrave Macmillan, New York, 273-98.

Ritchie, J. and Lewis, J. (eds) 2003. Qualitative Research Practice: A Guide for Social Science Students and Researchers. Sage, London.

Ritchie, J. and Spencer, L. 1994. Qualitative data analysis for applied policy research. In Byrman, A. and Burgess, R. G. (eds), Analyzing Qualitative Data. Routledge, London, $173-94$.

Rodrigues, R., Ilinca, S. and Schimdt, A. 2017. Income-rich and wealth-poor? The impact of measures of socio-economic status in the analysis of the distribution of long-term care use among older people. Health Economics. Published online 12 October, doi:10.1002/hec.3607.

Saraceno, C. 2010. Social inequalities in facing old-age dependency: a bi-generational perspective. Journal of European Social Policy, 2o, 1, 32-4.

Schwartz, K. 2013. Searching for a balance of responsibilities: OECD countries change elderly assistance policies. Annual Review of Public Health, 34, 397-41 2.

Spencer, L., Ritchie, J., O'Connor, W., Morrell, G. and Ormston, R. 2013. Analysis in practice. In Ritchie, J., Lewis, J., McNaughton, N. and Ormston, R. (eds), Qualitative Research Practice: A Guide for Social Science Students and Researchers. Second edition, Sage, London, $295^{-345}$.

Thorslund, M., Bergmark, A. and Parker, M. G. 1997. Difficult decisions on care and services for elderly people: the dilemma of setting priorities in the welfare state. Scandinavian Journal of Social Welfare, 6, 3, 197-206. 
2084 Cristiano Gori

Waldhausen, A. 2014. Care services in crisis? Long-term care in times of European economic and financial crisis. Working Paper 8, Observatory for Sociopolitical Development in Europe, Frankfurt, Germany.

Accepted 28 March 20I 8 ; first published online 6 May 2018

Address for correspondence:

Cristiano Gori,

Department of Sociology and Social Research,

University of Trento,

Via Verdi 26,

38122 - Trento, Italy

E-mail: cristiano.gori@unitn.it 